\title{
KILAT
}

Vol. 9, No. 1, April 2020, P-ISSN 2089-1245, E-ISSN 2655-4925

DOI: https://doi.org/10.33322/kilat.v9i1.761

\section{Short Term Load Forecasting Menggunakan Metode Koefisien}

\author{
Yosefin \\ PLN UPDL Semarang, PLN Pusdiklat, Indonesia \\ yosefin10yang@gmail.com
}

\begin{abstract}
Electrical energy has a very important role in national economic growth. With the electrical energy requirements, it is necessary to operate an economical, reliable and quality system. The creation of a template for operating load forecasting for the Java-Bali system uses a coefficient method to calculate weekly loads, daily loads, and loads per $1 / 2$ hour which is more user friendly. After this Load Forecasting template is applied, the result is a more efficient load deepening in terms of file size and time, and is more effective with the results of the calculation of electric energy (1.71\%), electricity load $(0.85 \%)$, and load factor $79 \%$ from planning data and manual realization.
\end{abstract}

Keywords: Template, coefficient method, electrical energy, electric load, load factor

\section{ABSTRAK}

Energi listrik memiliki peranan yang sangat penting dalam pertumbuhan ekonomi nasional. Dengan kebutuhan energi listrik tersebut maka diperlukan pengoperasian sistem yang ekonomis, andal serta bermutu. Pembuatan template prakiraan beban operasi sistem Jawa Bali menggunakan metode koefisien untuk menghitung beban mingguan, beban harian, dan beban per 1/2 jam yang lebih user friendly. Setelah diterapkan template Load Forecasting ini maka hasilnya adalah peralaman beban lebih efisien dalam hal ukuran file dan waktu, serta lebih efektif dengan hasil selisi perhitungan energi listrik $(1,71 \%)$, beban listrik $(0,85 \%)$, dan load factor $79 \%$ dari data perencanaan dan realisasi manual.

Kata kunci: Template, Metode koefisien, energi listrik, beban puncak, load factor 


\section{PENDAHULUAN}

Pertumbuhan Energi listrik terus meningkat dari waktu ke waktu sebanding dengan meningkatnya pertumbuhan ekonomi masyarakat. Untuk memenuhi kebutuhan energi listrik yang terus meningkat tersebut maka dibutuhkan perencanaan sistem tenaga listrik yang ekonomis, andal, dan bermutu.

Salah satu masalah yang ada di PT PLN P3B Interkoneksi Jawa Bali adalah Keterbatasan personil yang mampu membuat prakiraan beban sehingga diperlukan sistem prakiraan beban yang user friendly yang mampu dipakai oleh semua personil .

Dalam melakukan prakiraan beban operasi sistem banyak metode yang dapat digunakan yaitu Fuzzy Logic[1][2], AI[3], ARIMA[4], Koefisien dan lain-lain. PT PLN P3B Interkoneksi Jawa Bali dalam melakukan prakiraan beban sendiri menggunakan metode koefisien .

Dengan pembuatan template Load Forecasting yang user friendly dan analisis prakiraan beban menggunakan metode koefisien maka deviasi antara perencanaan $(\mathrm{N})$ dengan Realisasi yang dibuat akan semakin kecil.

\section{METODE/PERANCANGAN PENELITIAN}

Metode yang digunakan untuk melakukan untuk mengidentifikasi permasalahan ialah dengan metode Fishbone Diagram Analysis. Hasil identifikasi masalah dapat dilihat di Gambar 1.

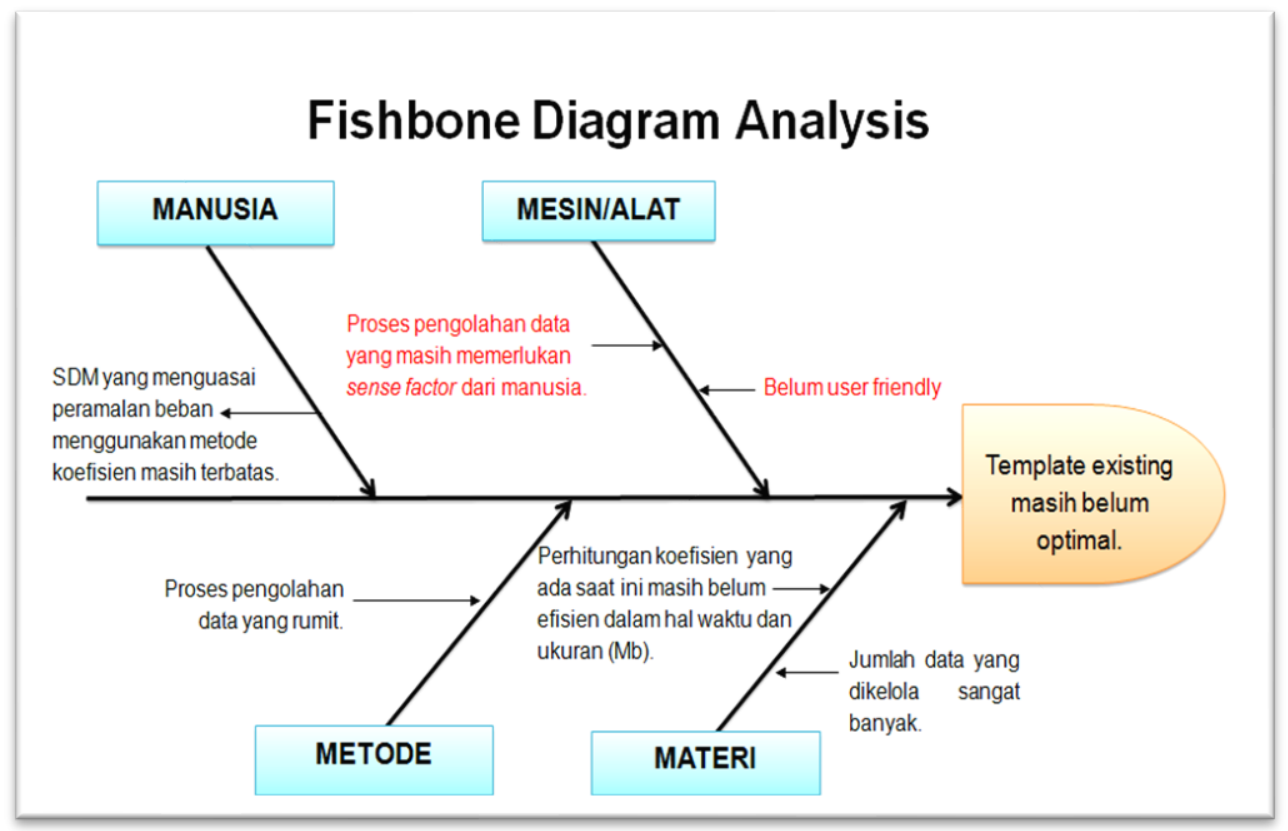

Gambar 1. Fishbone diagram analysis

Studi Literatur: jurnal-jurnal, buku - buku dan internet yang dapat dijadikan sebagai acuan dalam melakukan studi ini.

Pencarian Informasi dan Data: informasi dan data diperoleh dari PT. PLN (Persero) P3B. Pengolahan Data: Pengelolaan data beban realisasi untuk melakukan peramalan beban jangka pendek dengan bantuan software MS.Excel.

Analisa Data: Analisa data menggunakan metode koefisien dengan dibantun software MS.Excel. 


\section{KILAT}

Vol. 9, No. 1, April 2020, P-ISSN 2089-1245, E-ISSN 2655-4925

DOI: https://doi.org/10.33322/kilat.v9i1.761

\section{PEMBAHASAN DAN HASIL}

\subsection{PEMBAHASAN}

Dalam proses peramalan beban menggunakan metode koefisien, diperlukan sebuah template dalam format excel yang bertujuan untuk memudahkan user atau pengguna dalam melakukan proses pengolahan data-data hingga menghasilkan sebuah output load forecasting yang akurat dengan small size data.

Template yang dibuat adalah sebuah template yang bersifat userfriendly sehingga dapat digunakan oleh siapa saja yang ingin melakukan peramalan beban. Pembuatan template berikut ini dibuat dengan menggunakan automatisasi dan menghilangkan proses manual yang kurang diperlukan. Template ini juga berisikan SOP (Standar Operasi Prosedur) yang berfungsi sebagai pemandu user dalam menggunakannya. Data energi dapat dilihat di Gambar 2.

Metode koefisien merupakan suatu metode yang mengalikan (range $0 \mathrm{~s} / \mathrm{d} 1$ ) dengan data statistic yang real. Beberapa pendekatan yang bisa digunakan yaitu Linier, Exponensial, Logarirmic, Polinomial. Tetapi dalam case ini menggunakan pendekatan Linier.

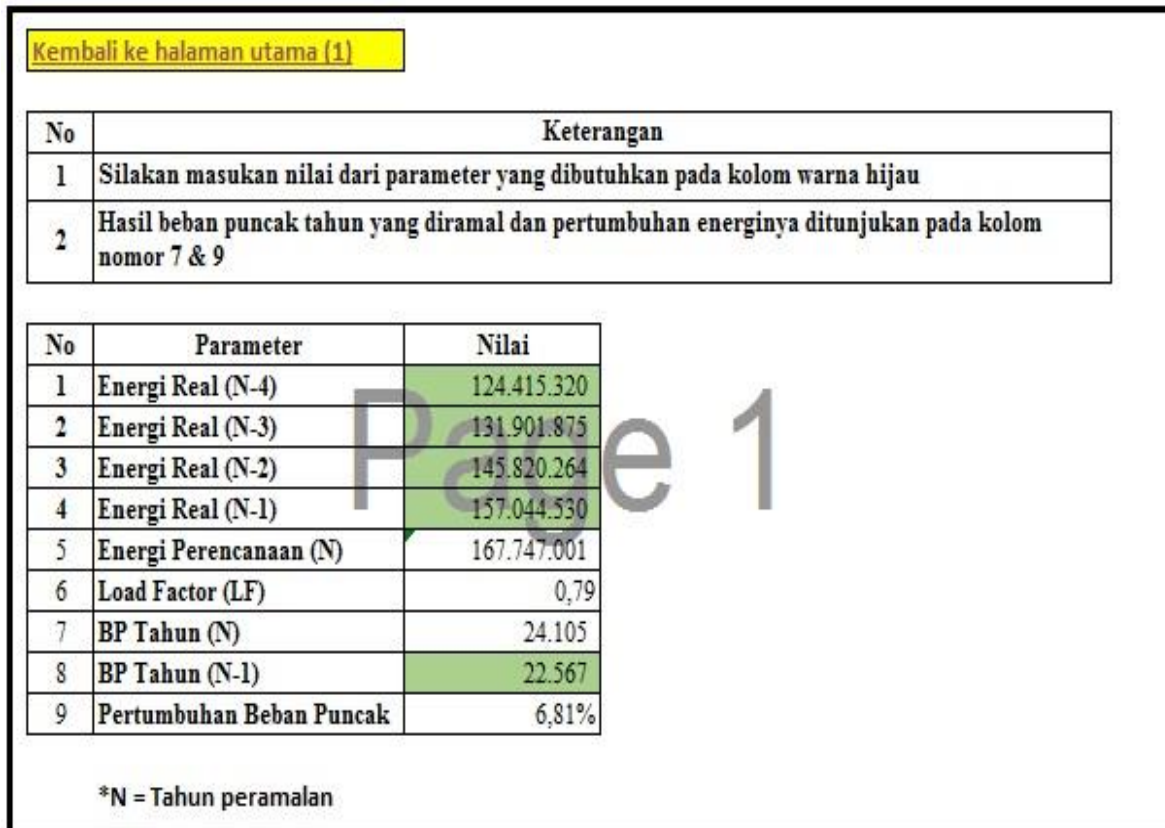

Gambar 2. Tampilan Halaman Depan Template

Energi tahunan tahun 2014 ialah jumlah energi listrik yang di hasilkan oleh pembangkit per jam ataupun per setengah jam dalam satuan MWH (Mega Watt Hours). Dalam mencari energi tahun 2014 kita menggunakan pendekatan regresi linier $(\mathrm{Y}=\mathrm{a}+\mathrm{bX})$.

Data urutan realisasi energi mulai tahun 2010 sampai 2014 ; 124.415,32 GWH, 131.901,86 GWH, 145.820,26 GWH, 157.044,53 GWH. [5]

Dengan menggunakan rumus excel $:=$ forecast $(x$, knows_y's, knows_x's) didapat prakiraan energi tahunan tahun 2014 sebesar : $167.747 .001 \mathrm{MWH}$. Langgam pertumbuhan Energi dari tahun 2010 s/d 2014 dapat dilihat di Gambar 3. 
Pertumbuhan Energi Dari Tahun 2010 s/d 2014

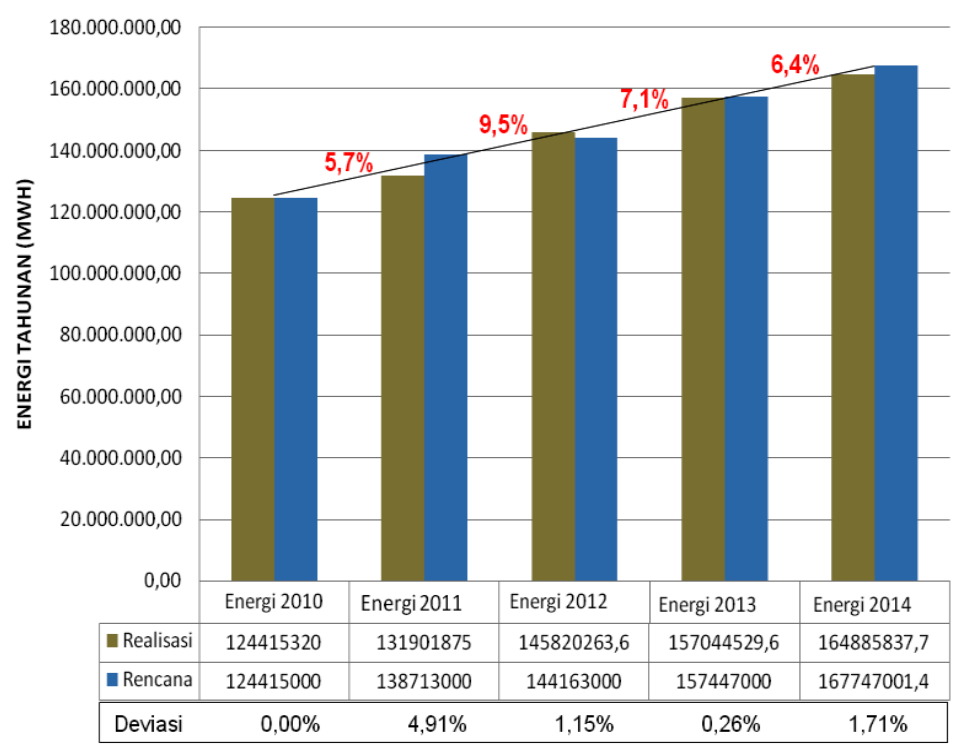

Gambar 3. Pertumbuhan Energi dari tahun 2010 s.d 2014 [5]

Perhitungan load factor tahunan tahun 2014 adalah Energi realisasi di tahun N-1 dibanding durasi dan beban puncak tertinggi di tahun $\mathrm{N}$-;

Sehingga di dapat load factor tahun 2014 sebesar :79\% . [5]

Perhitungan prakiraan beban puncak tahunan tahun 2014 ialah prakiraan energi (N) dibanding waktu dan factor beban $(\mathrm{N})$

Sehingga di dapat beban puncak (N) tahun 2014 sebesar :24.105 MW

Sedangkan beban Realisasi 23.900 MW [5]

maka persentase selisi BP Tahunan sebesar $\mathbf{0 , 8 5 \%}$

Perhitungan Koefisien tahunan $(\mathbf{N})$ adalah beban rata-rata tiap tahun dibandingkan dengan maksimum beban rata-rata.

Koefisien mingguan $(\mathbf{N})$ ialah realisasi nilai beban rata-rata mingguan dari $(\mathrm{N}-4)$ s/d $(\mathrm{N}-1)$ tahun dibagi nilai realisasi rata-rata maksimum bebandari $(\mathrm{N}-4)$ s/d $(\mathrm{N}-1)$ tahun.

Beban puncak mingguan (N) tahun 2014 di dapat dari perhitungan beban puncak tahunan dikali koefisien mingguan tahun 2014. Langgam pertumbuhan BP Mingguan 2014 dapat dilihat di Gambar 4. 


\section{KILAT}

Vol. 9, No. 1, April 2020, P-ISSN 2089-1245, E-ISSN 2655-4925

DOI: https://doi.org/10.33322/kilat.v9i1.761

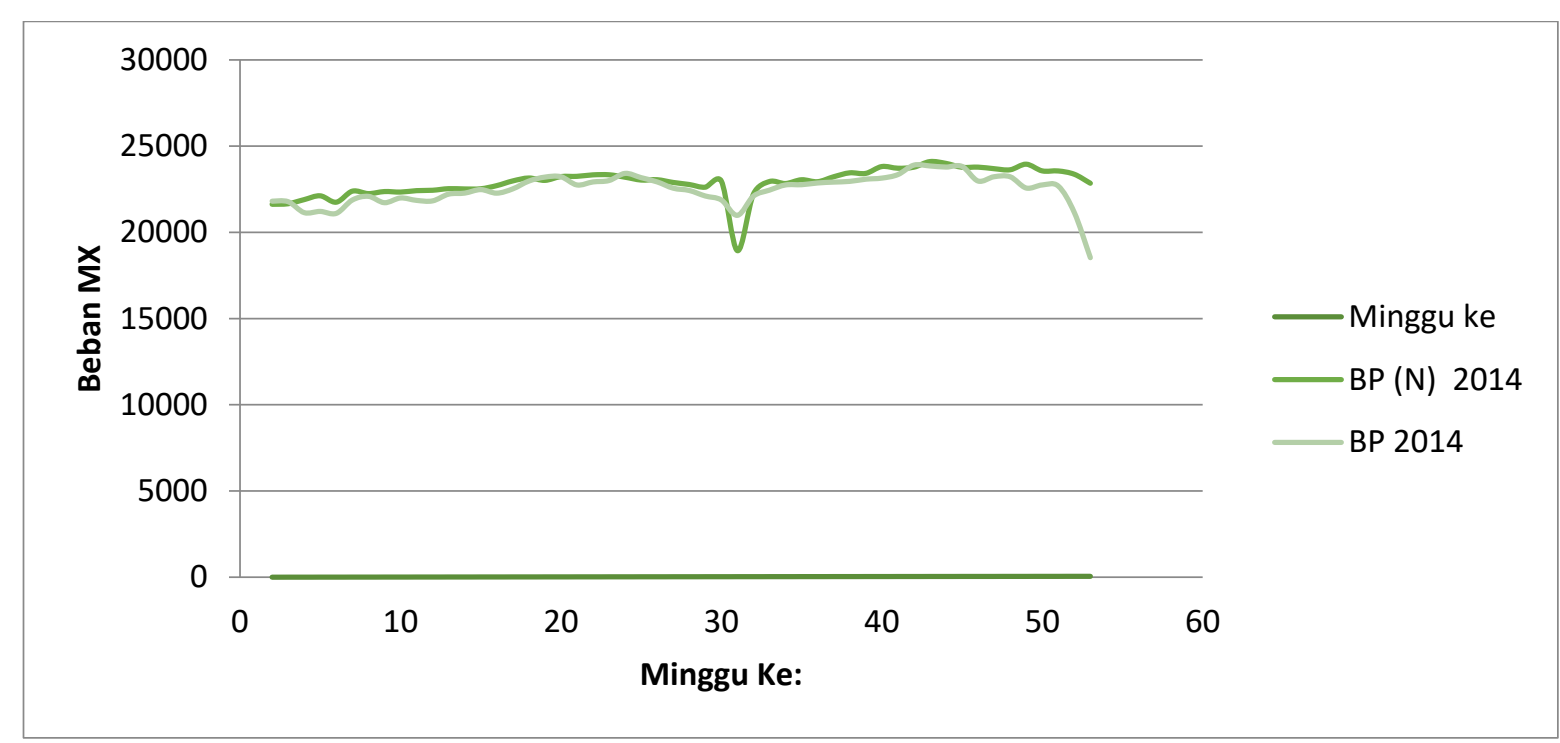

Gambar 4. Langgam BP Mingguan tahun 2014

Beban puncak harian ialah perkalian antara koefisien harian dikali dengan beban puncak mingguan. Langgam pertumbuhan BP Harian 2014 dapat dilihat di Gambar 5.

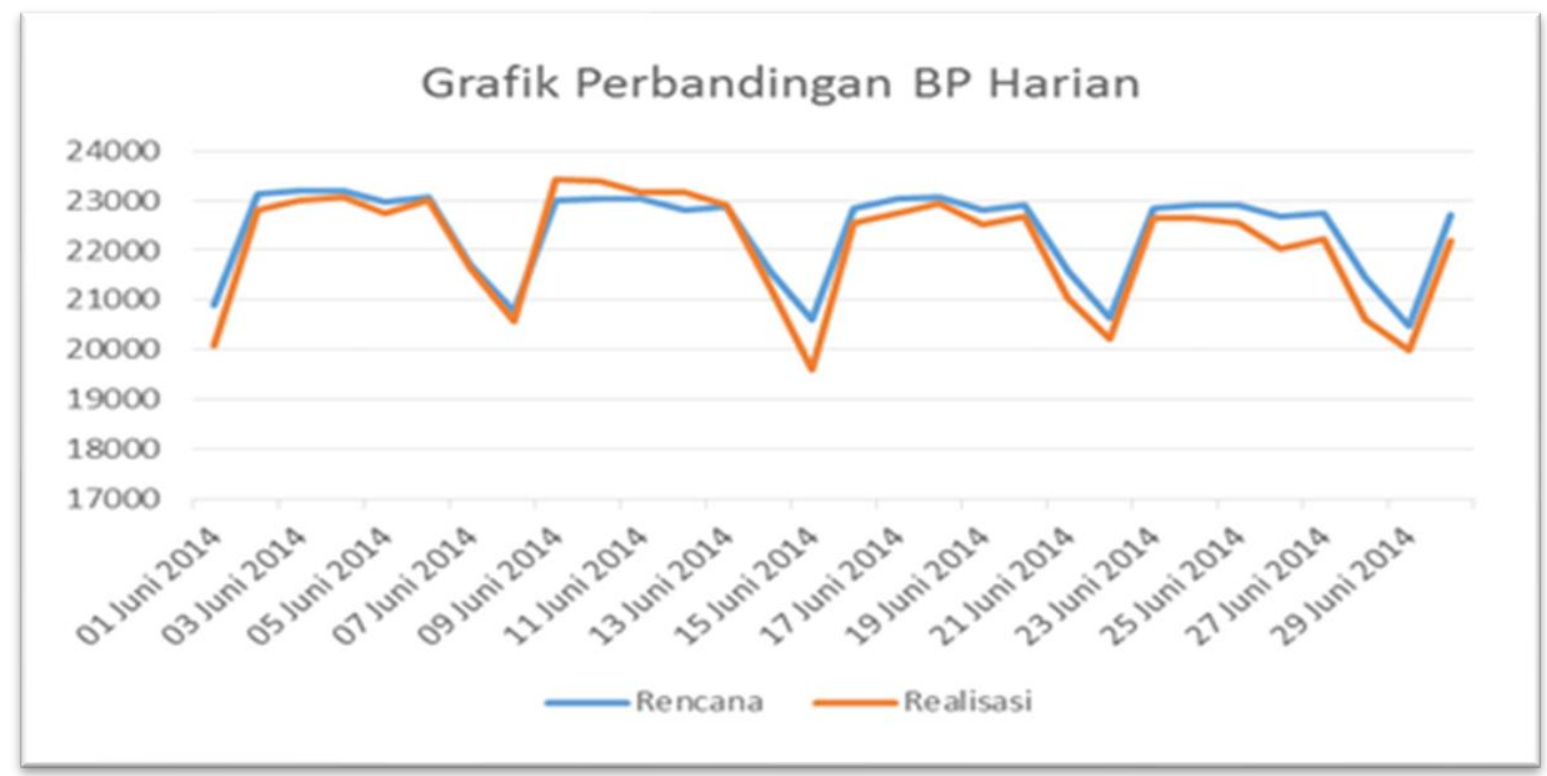

Gambar 5. Langgam BP Harian tahun 2014

Beban puncak Per $1 / 2$ Jam tahun 2014 di dapat dari perhitungan beban puncak harian dikali koefisien Per $1 / 2$ jam tahun 2014. Dengan Formula: BP per $1 / 2$ jam= Koefisien $1 / 2$ jam x BP harian. Untuk perhitungan Beban bisa dilihat di tabel 1. 
Tabel 1. Perhitungan BP per setengahjam tanggal 5 Jan'2014.

\begin{tabular}{|c|c|c|c|c|}
\hline \multicolumn{5}{|c|}{ Beban 1/2 Jam 05/01/2014 } \\
\hline Tanggal & Jam & $\begin{array}{c}\text { Rencana } \\
2014\end{array}$ & $\begin{array}{c}\text { Realisasi } \\
2014\end{array}$ & MAPE \\
\hline $05 / 01 / 2014$ & $0: 30$ & 16110 & 16160 & $0.31 \%$ \\
\hline $05 / 01 / 2014$ & $1: 00$ & 15849 & 15950 & $0.64 \%$ \\
\hline $05 / 01 / 2014$ & $1: 30$ & 15649 & 15711 & $0.39 \%$ \\
\hline $05 / 01 / 2014$ & 2:00 & 15470 & 15539 & $0.44 \%$ \\
\hline 05/01/2014 & $2: 30$ & 15309 & 15464 & $1.00 \%$ \\
\hline $05 / 01 / 2014$ & 3:00 & 15169 & 15295 & $0.83 \%$ \\
\hline $05 / 01 / 2014$ & $3: 30$ & 15100 & 15175 & $0.49 \%$ \\
\hline $05 / 01 / 2014$ & 4:00 & 15095 & 15220 & $0.82 \%$ \\
\hline $05 / 01 / 2014$ & $4: 30$ & 15276 & 15493 & $1.40 \%$ \\
\hline $05 / 01 / 2014$ & $5: 00$ & 15479 & 15751 & $1.73 \%$ \\
\hline 05/01/2014 & $5: 30$ & 15630 & 15738 & $0.69 \%$ \\
\hline $05 / 01 / 2014$ & $6: 00$ & 15491 & 15388 & $0.67 \%$ \\
\hline $05 / 01 / 2014$ & $6: 30$ & 15318 & 15050 & $1.78 \%$ \\
\hline 05/01/2014 & 7:00 & 15268 & 14831 & $2.94 \%$ \\
\hline 05/01/2014 & $7: 30$ & 15314 & 14924 & $2.61 \%$ \\
\hline $05 / 01 / 2014$ & $8: 00$ & 15394 & 15044 & $2.33 \%$ \\
\hline 05/01/2014 & $8: 30$ & 15564 & 15232 & $2.18 \%$ \\
\hline $05 / 01 / 2014$ & 9:00 & 15839 & 15344 & $3.23 \%$ \\
\hline
\end{tabular}

\begin{tabular}{|c|c|c|c|c|}
\hline Tanggal & Jam & $\begin{array}{c}\text { Rencana } \\
2014\end{array}$ & $\begin{array}{c}\text { Realisasi } \\
2014\end{array}$ & MAPE \\
\hline 05/01/2014 & 10:00 & 16132 & 15812 & $2.02 \%$ \\
\hline 05/01/2014 & $10: 30$ & 16142 & 15897 & $1.54 \%$ \\
\hline 05/01/2014 & 11:00 & 16150 & 15883 & $1.68 \%$ \\
\hline 05/01/2014 & $11: 30$ & 16142 & 15950 & $1.20 \%$ \\
\hline 05/01/2014 & $12: 00$ & 16029 & 15728 & $1.91 \%$ \\
\hline 05/01/2014 & $12: 30$ & 15751 & 15711 & $0.26 \%$ \\
\hline 05/01/2014 & 13:00 & 15823 & 15916 & $0.59 \%$ \\
\hline 05/01/2014 & $13: 30$ & 15979 & 15922 & $0.36 \%$ \\
\hline 05/01/2014 & $14: 00$ & 15916 & 15948 & $0.20 \%$ \\
\hline 05/01/2014 & $14: 30$ & 15866 & 15900 & $0.22 \%$ \\
\hline 05/01/2014 & $15: 00$ & 15855 & 15743 & $0.71 \%$ \\
\hline 05/01/2014 & $15: 30$ & 15984 & 15802 & $1.15 \%$ \\
\hline 05/01/2014 & $16: 30$ & 16462 & 16319 & $0.87 \%$ \\
\hline 05/01/2014 & 17:00 & 16761 & 16595 & $1.00 \%$ \\
\hline 05/01/2014 & $17: 30$ & 17357 & 17137 & $1.28 \%$ \\
\hline 05/01/2014 & 18:00 & 18224 & 18124 & $0.56 \%$ \\
\hline 05/01/2014 & $18: 30$ & 19174 & 18791 & $2.04 \%$ \\
\hline 05/01/2014 & 19:00 & 19330 & 18938 & $2.07 \%$ \\
\hline 05/01/2014 & $19: 30$ & 19355 & 18949 & $2.14 \%$ \\
\hline
\end{tabular}




\section{KILAT}

Vol. 9, No. 1, April 2020, P-ISSN 2089-1245, E-ISSN 2655-4925

DOI: https://doi.org/10.33322/kilat.v9i1.761

\begin{tabular}{lllll}
\hline $\mathbf{0 5 / 0 1 / 2 0 1 4}$ & $20: 00$ & 19293 & 18868 & $2.25 \%$ \\
\hline $\mathbf{0 5 / 0 1 / 2 0 1 4}$ & $20: 30$ & 19120 & 18712 & $2.18 \%$ \\
$\mathbf{0 5 / 0 1 / 2 0 1 4}$ & $21: 00$ & 18771 & 18319 & $2.47 \%$ \\
$\mathbf{0 5 / 0 1 / 2 0 1 4}$ & $21: 30$ & 18248 & 17746 & $2.82 \%$ \\
\hline $\mathbf{0 5 / 0 1 / 2 0 1 4}$ & $22: 00$ & 17750 & 17153 & $3.48 \%$ \\
$\mathbf{0 5 / 0 1 / 2 0 1 4}$ & $22: 30$ & 17273 & 16809 & $2.76 \%$ \\
$\mathbf{0 5 / 0 1 / 2 0 1 4}$ & $23: 00$ & 16751 & 16434 & $1.93 \%$ \\
$\mathbf{0 5 / 0 1 / 2 0 1 4}$ & $23: 30$ & 16403 & 16028 & $2.34 \%$ \\
\hline $\mathbf{0 5} / \mathbf{0 1} / \mathbf{2 0 1 4}$ & $0: 00$ & 16054 & 15713 & $2.17 \%$ \\
& & & Rata-rata & $1.48 \%$ \\
\hline
\end{tabular}

Dari contoh Gambar 6 di bawah dapat dilihat pola beban per $1 \frac{1}{2}$ jam . Beban Puncak bisa dilihat sejak pukul 18.30s/d20.00 WIB

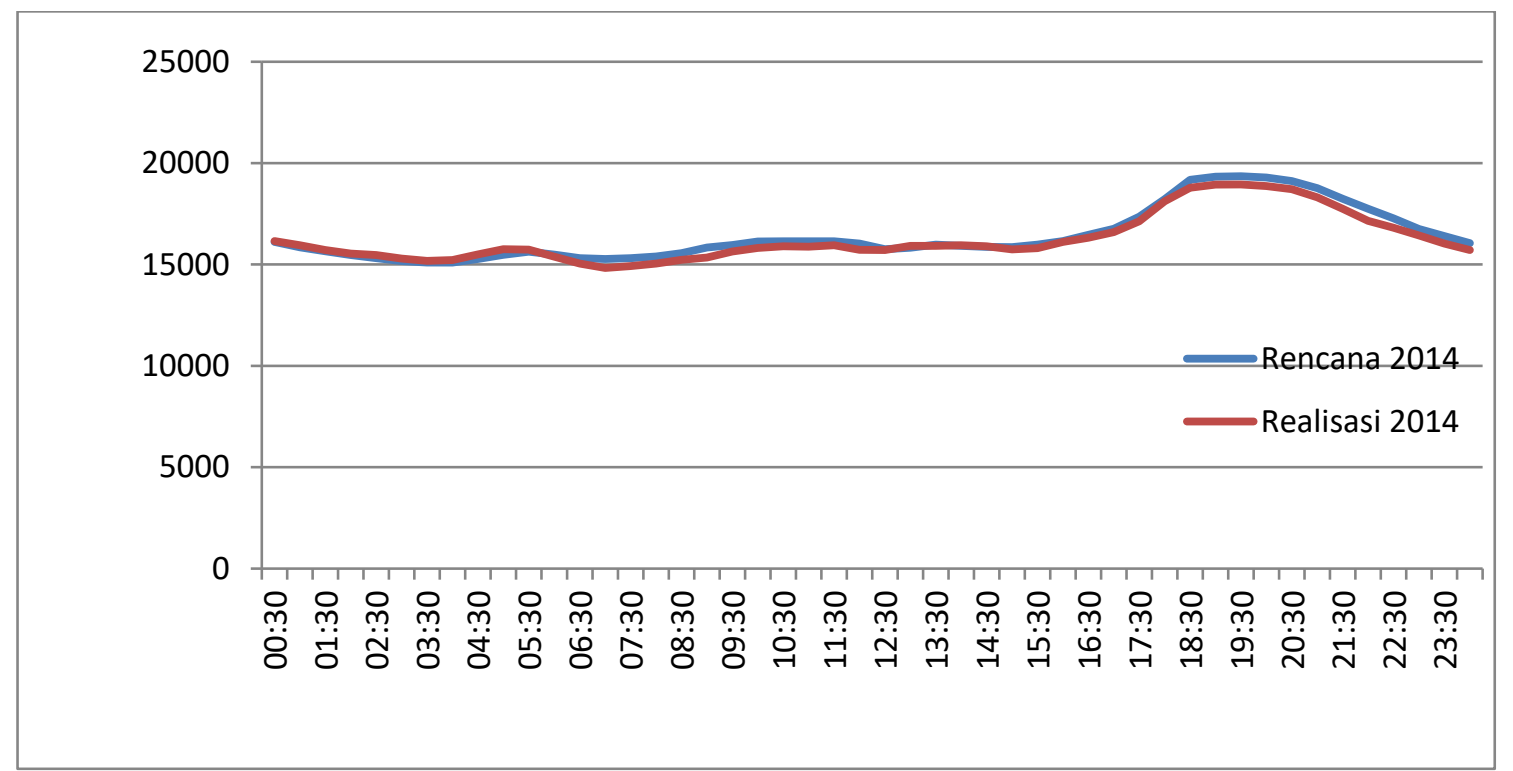

Gambar 6. Langgam per $1 / 2$ di tanggal

5 Januari 2014

\subsection{HASIL}

Pembuatan Template Excell Load Forecasting PLN P3B Interkoneksi Jawa Bali tahun 2014 lebih efisien dalam hal ukuran file dan waktu, serta lebih efektif dengan hasil selisi perhitungan energi listrik $(1,71 \%)$, beban listrik $(0,85 \%)$, dan load factor $79 \%$ dari data perencanaan dan realisasi manual. 


\section{KESIMPULAN \& SARAN}

\subsection{KESIMPULAN}

Pembuatan template prakiraan beban operasi system 2014 ini mampu digunakan oleh banyak personil (User friendly) di PLN P3B Interkoneksi jawa bali. Dan penerapananya telah efektif dan efisien dalam melakukan prakiraan beban.

\subsection{SARAN}

Prakiraan Beban operasi system kedepannya bisa terintegrasi dengan SCADA sehingga bisa langsung diramal beban secara realtime.

\section{UCAPAN TERIMA KASIH}

Ucapan terima kasih buat bpk/ibu pegawai PLN P3B yang atas bimbingan dan dukungan selama pembuatan template excell prakiraan beban operasi system P3B tahun 2014.

\section{DAFTAR PUSTAKA}

[1] H. Shayeghi, H. a Shayanfar, and G. Azimi, "a Hybrid Particle Swarm Optimization Back Propagation Algorithm for Short Term Load Forecasting," Int. J. Tech. Phys. Probl. Eng., vol. 2, no. 4, pp. 12-22, 2010.

[2] A. G. Abdullah, "Short Term Load Forecasting (Stlf) Melalui Pendekatan Logika Fuzzy," Electrans, no. November, pp. 1-6, 2008.

[3] F. Dhimas Syahfitra, R. Syahputra, and K. Trinanda Putra, "Implementation of Backpropagation Artificial Neural Network as a Forecasting System of Power Transformer Peak Load at Bumiayu Substation," J. Electr. Technol. UMY, vol. 1, no. 3, pp. 118-125, 2017.

[4] N. Mohamecl, M. H. Ahmad, and Suhartono, "Forecasting short term load demand using double seasonal arima model," World Appl. Sci. J., vol. 13, no. 1, pp. 27-35, 2011.

[5] PLN, "Rencana Usaha Penyediaan Tenaga Listrik PT PLN (Persero) 2013-2022," p. 510, 2013. 